\title{
Presencia y ausencia del Humanismo en la Península Ibérica
}

\author{
Julia BuTIÑÁ JiMÉNEZ
}

UNED

Reial Acadèmia de Bones Lletres

juliabutinya@gmail.com

\section{RESUMEN}

Se traza una vista de conjunto acerca de la situación actual de los estudios sobre el Humanismo en la Península Ibérica, señalando el itinerario más reciente, así como las consecuciones y los puntos pendientes.

Palabras clave: Comparatismo ibérico, movimiento humanista, literatura humanística de la Corona de Aragón, proyección peninsular.

\section{Presence and Absence of Humanism in the Iberian Peninsula}

\begin{abstract}
An insight on the state of the arts in Humanism studies in the Iberian Peninsula is sketched in this article, that states the most recent itinerary, as well as the achievements and the pending issues.
\end{abstract}

Keywords: Iberian comparative studies, Humanism, humanistic literature in the Crown of Aragon, Iberian projection.

\section{Introducción}

El Humanismo es un movimiento poco conocido, principalmente por falta de precisión en su misma denominación, desacuerdo generado por las frecuentes polémicas, que han llegado a cuestionar incluso su existencia. Si hay innumerables definiciones para el Humanismo, una muy general podría centrarse en el recorrido que marcan los considerados como principales textos literarios, y que en lugar destacado vienen determinados por el clasicismo ${ }^{1}$. Y si desde una abstracción el con-

${ }^{1}$ Una perspectiva reciente se encuentra en J. Butiñá y A. Cortijo Ocaña (2011) y J. Butiñá (2012a). 
cepto es más amplio que el estrictamente textual, si reconocemos la energía del espíritu, hay que conceder un lugar prioritario a los textos, donde este ha quedado preferentemente reflejado a lo largo de la Historia. Fundándonos en ello e intentando estrechar el círculo, puede darse un gran paso adelante, entendiendo o aceptando -según es común como la más relevante para la dinámica humanística- la línea que en Occidente transmite la Antigüedad clásica, que persiste encumbrada a lo largo de la Edad Media y se renueva hacia finales de esta era desde el mismo cristianismo.

Rechazamos desde aquí cualquier posición excluyente, sea por época, por lenguas o por enfoques restringidos ${ }^{2}$, dado que aquella línea, sobre la que se asentará posteriormente el Renacimiento ${ }^{3}$ y que marca definitivamente la Europa moderna, es una corriente firme y coherente, artística, moral ${ }^{4}$ y de pensamiento ${ }^{5}$, que no permite trocearse o ser desgajada; es decir, al escindir una lengua, una parcela o una época determinada, se desvalora o merma su entidad, dado que forzosamente un movimiento tan global se manifiesta adecuándose a distintas expresiones lingüísticas, espacios y momentos.

Como en todos los movimientos, hay figuras motoras que repercuten enormemente; figuras puras que quizás influyen poco o son apenas conocidas, y figuras mixtas que presentan notas alternadamente, bien por estar muy ligadas al pasado, bien por adoptar los nuevos rasgos superficialmente y debido en gran parte al efecto del avance de la moda ${ }^{6}$. Estas últimas, que constituyen la mayo-

${ }^{2}$ Una de las causas de la falta de consenso crítico se cifra en las exclusiones a raíz de planteamientos que se pueden percibir ya diferenciados en su origen (González Rolán et al. 2002: 60-62).

${ }^{3}$ El Renacimiento no nace de unos hombres a los que se les antoja y que se empeñan en copiar a los clásicos, según admiran de manera simplificada los turistas, sino que es resultado del empuje humanista y suele ser donde aboca este movimiento, al que este ha hecho de motor; por lo que es preciso distinguir ambos movimientos adecuadamente a efectos de delimitaciones y de una correcta clarificación (vid. Batllori 1995).

${ }^{4}$ La liberación humana que conllevan el fuerte racionalismo y el naturalismo exigía la revisión ética de los esquemas anteriores, de donde se desprende la renovación de las virtudes cristianas, la cual se efectúa a la luz del clasicismo. Así pues, hay figuras emblemáticas como humanistas pero que principalmente lo son en aspectos formales, pues su moral está muy alejada de lo que significaba aquel cambio; y esto es así desde Petrarca a fra Antoni Canals (m. 1419) o Pere Miquel Carbonell (14341517) (Rubió i Balaguer 1990: 78-79).

${ }_{5}$ Dada su amplitud, pues afecta a toda la persona humana, no implica una doctrina determinada, es decir, en rigor no es un movimiento filosófico, de modo que no se suele incluir en historias de la Filosofía. Así, algunos autores, como J. Hirschberger, pasan directamente de la Edad Media, donde se hallan sus raíces, a Ficino o Pico della Mirandola como pensadores renacentistas.

${ }^{6}$ Ello anticipa que no puede trazarse una raya para calificar a obras ni autores, pues las figuras nítidas son las más escasas; por otro lado, no por ser más prestigiado o influyente un autor hay que otorgarle un mayor grado humanístico. Hay que tener en cuenta que es un movimiento cultural de resonancia plural y no específico de una cualidad determinada; los trabajos del profesor R. Da Costa (2012a, $2012 \mathrm{~b}, 2012 \mathrm{c}$ ), que atienden a la historia, al pensamiento y a la expresión artística, permiten observar esta apreciación desde una perspectiva amplia. Así, no porque el Curial e Güelfa defienda el amor honesto es menos humanística (vid. Hauf 2012), ya que como corriente ideológica absorbe las dos tradiciones (vid. Tavani 1996: 148-177); además, suscriben aquel tipo de amor bien figuras de la Antigüe- 
ría, explican de modo muy principal la desembocadura de movimiento tan denso en las actitudes renacentistas, pues, sin que ello tenga que implicar que no sean auténticas en su prurito clasicista, sí son menos revolucionarias; piénsese en un Joan Roís de Corella (1435-1497). Mientras que el Humanismo es revolucionario por definición, dado que en su objetivo de renovación pretende volver a aquel pasado integralmente, lo que supone una voluntad de rompimiento con los poderes anteriores, sea mentales, escolásticos, eclesiales, moralidad medievalizante, etc. Y si los renacentistas, que en cada cultura tienen su momento, viven aquel ímpetu de modo menos virulento -en parte porque la sociedad misma ha ido aceptándolo-, también ha habido humanistas de gran ambivalencia o incluso suavidad ${ }^{7}$.

\section{Raíces y proyección peninsular del Humanismo}

No vamos a remontarnos a los primeros siglos y rescates -si bien incluso en un somero escarceo no puede prescindirse de san Agustín por la trascendencia que tuvieron sobre todo dos de sus grandes obras, el De Civitate Dei y las Confessio$n e s^{8}$-; ni siquiera nos referiremos al preludio humanístico a inicios del siglo XII, muy a pesar de que autores como Hildeberto de Lavardin sea considerado normalmente por ese motivo como humanista9 . Para que el movimiento alcance la Península Ibérica hay que adelantar un poco más en el tiempo y llegar al siglo XIV, cuando en la Corona de Aragón, dadas sus relaciones con Italia ${ }^{10}$, y también con Grecia, se documenta un autor como Bernat Metge (c. 1340-1346-1413), plenamente sensible a esta recuperación, en sus facetas de indignación y rechazo del pasado próximo y vigente, así como de asimilación admirativa del pasado clasicista, tan reverenciado como incomprendido. A favor de la dignificación humana, entre la asimilación del clasicismo y la rectificación de la mentalidad tradicional. Una obra de Bernat Metge muy significativa es su traducción de Valter e Griselda (1388), que continúa

dad, como Lucrecia, bien humanistas tardíos, como Luis Vives (1492-1540) o fray Luis de León (c. 1527-1528-1591) en sus obras sobre la mujer casada.

${ }^{7}$ Es bien conocido el equilibrio de una obra como el Curial e Güelfa, de un humanismo temprano aún, en pleno siglo XV, pero más sereno y menos combativo que el de un Bernat Metge, pues parece responder a la explicación lógica de insertarse en un ambiente ya sólidamente humanístico como era el de la corte napolitana. He aquí cómo Baco convierte a Curial con palabras de san Gregorio: «Vilescunt temporalia cum considerantur eterna» (Curial 2007: 354).

${ }^{8}$ Sobre la influencia del agustinismo en la modernidad, vid. W. J. Bowsma (2001: 39), y sobre la distinta modernidad de una u otra obra, J. Butiñá (2003b: 94).

${ }^{9}$ Este autor, junto con otros que se hallan ya en la línea de una secularización e incluso de una ovidianización, forman parte de la continuación de la Antigüedad que, renovada por el cristianismo, configura Occidente (vid. Haskins 1976).

10 Entre muchos trabajos y tras la precedencia de eruditos como M. de Riquer $(1934,1964)$, G. Tavani (1996) y del profesor M. Batllori (1995), ajustándose a la literatura catalana en un contexto comparado, puede verse J. Butiñá (2006a). 
la corriente traductora del último relato del Decamerón que había comenzado Francesco Petrarca ${ }^{11}$.

Situándonos en este punto se abren multitud de incógnitas y puntos pendientes de investigación: ¿qué conoció Bernat Metge de los griegos en Aviñón?, ¿hubo contactos desde el estudio de Juan Fernández de Heredia (1310?-1396) que implicaran la nueva sensibilidad ${ }^{12}$ ? Preguntas formuladas solo a modo de ejemplo, pero que prioritariamente apuntan a la sombra helénica que caracteriza al territorio catalanoaragonés, pues aquella suele aparecer más tarde en otros lugares. Llegados al siglo $\mathrm{XV}$, la deuda investigadora se intensifica, precisamente cuando la corte napolitana del Magnánimo -humanista por antonomasia- es lugar de encuentro de humanistas catalanes y castellanos que podría abastecer luz sobre ese recorrido y relaciones ${ }^{13}$. Por otro lado, la expansión hacia el Oeste es evidente dado que en el XVI vemos síntomas claros en Portugal ${ }^{14}$. El estudio de este movimiento, por tanto, no debe prescindir de zonas a las que llega más tarde, o que acusan manifestaciones similares en momentos ya alejados del impacto principal, a fines del Medioevo; como es el caso de la literatura euskera en la Península ${ }^{15}$.

El espacio más discutido en los últimos decenios ha sido el del llamado humanismo catalán, a causa de una fuerte negación surgida a partir de la década de los años ochenta, que llevó a desarraigar el concepto prácticamente en la crítica y ámbitos catalanes, es decir, los de origen hispánico (vid. Butiñá 2009, 2010, 2012d). Desde los años noventa empecé a publicar en una dirección positiva -desde la reivindicación del sello humanista del Curial e Güelfa $(c .1435-1462)^{16}$, y al socaire de

11 Sobre el Griselda metgiano y sobre la importancia de la traducción de estas letras en el Medioevo, vid. Butiñá (2002a, 2012b: 102-136).

12 En eHumanista / IVITRA se está preparando un volumen titulado Grècia i les lletres catalanes, tema en el que hay que sopesar de antemano la influencia y las relaciones con las traducciones del estudio de Fernández de Heredia; tema además muy nuevo por desconocido, pero que está en el ojo del huracán en la actualidad a causa del discutido papel de dichas letras en aquel momento.

${ }^{13}$ Invitan a la investigación muchas parcelas pendientes de análisis; una de ellas se refiere a las traducciones catalanas realizadas en el siglo XVI en Alcalá de Henares, lugar muy significativo para el Humanismo. Pero lamentablemente hoy, en vez de aportarse novedades, se siguen repitiendo tópicos, como la relación de Jordi de Sant Jordi (1399-1424) con el Marqués de Santillana. Sobre la recepción del Humanismo, vid. J. Butiñá (2004).

14 Para los distintos puntos de este párrafo se remite al libro de M. Batllori (1995: 79-86). Una muestra concreta de las posibilidades que se abren ante la temprana apertura al caudal helénico se halla en H. Guzmán (2009). Y para una visualización de este influjo en Bernat Metge, vid. A. Cortijo (2013) y también J. Butiñá y A. Cortijo Ocaña (2014).

15 Es frecuente, sin embargo, hallarse con invectivas ante el rastreo de la influencia humanista en estas letras, pero el hecho de que afloren en una época más tardía ocurre también en algunos países europeos, donde se estudia normalmente; así, el caso del humanismo polaco, que reúne obras de interés que responden a las notas de aquella corriente en fecha muy posterior. Sobre la literatura euskera pronunció una conferencia L. Otaegi (2011), con el explícito título de «En busca de un Arte Poética para la lengua vasca (siglos XVI y XVII)».

${ }^{16}$ Sobre Bernat Metge, vid. J. Butiñá (1989-1990); y sobre Curial, tras una hipótesis de autoría (Butiñá 1987-1988), publiqué una monografía (Butiñá 1999). Cabe añadir que sigo haciendo aportaciones en la misma dirección (en prensa $\mathrm{a}, \mathrm{b}$ ). 
los escritos del profesor M. Batllori- una serie de artículos, que desembocaron en 2006 en el último libro de una trilogía sobre aquellos orígenes ${ }^{17}$; de aquel entonces hay contados casos de investigadores a favor de esta corriente (G. Tavani, J. M. Ribera...). Con motivo del fallecimiento del sabio profesor coordiné un primer monográfico ${ }^{18}$, al que suceden cuatro volúmenes monográficos más con colaboraciones de procedencias muy variadas -entre ellas se cuenta con profesores de tierras catalanas-. Ahora bien, resultados directos, diálogo o incluso acuse de recepción no se han dado en la propia área científica, pues sigue dominando el vacío, quizás en parte por desconocimiento, o bien debido a la posición conocida en el mundo científico como de ninguneo, es decir la de esquivar algo por no merecer la discusión. Hay que reconocer, de todos modos, que actualmente ha cambiado el panorama al contar dentro de este espectro temático no sólo con una perspectiva internacional sino también con muy distintas especialidades ${ }^{19}$.

\section{La Corona de Aragón y la difusión peninsular del Humanismo}

Si nos adentramos en el autor que puede tomarse como el humanista más puro, junto con el de aquella novela ${ }^{20}$, Bernat Metge y Curial e Güelfa, y vamos a su obra principal, el diálogo Lo somni (1399), rápidamente entenderemos que no se le puede calificar de heretge epicuri, como se hace por parte de la crítica adversa al Humanismo. Pues los humanistas no son herejes; epicúreos, depende, pero esta no es nota que le reste entidad a un humanista. Es decir, difícilmente encajan en autor tan exquisito un sermón como el Sermó (s.f.), de apariencia inmoral, o un debate aparentemente medieval pero indudablemente burlesco como el Libre de Fortuna e Prudència $(1381)^{21}$, si no se leen desde el hálito del Humanismo.

Esta parcela del Humanismo, que en territorios como el valenciano ${ }^{22}$ ofrece un precioso hibridismo de medievalismo-humanismo-renacentismo hasta entrado el

17 Además del Curial, novela exquisitamente humanista, la componen un libro sobre Bernat Metge, representante purísimo del Humanismo, aun contándose entre sus primeros representantes, y otro sobre Ramon Llull, a quien hay que situar en los orígenes del movimiento (Butiná 2002b y 2006b, respectivamente).

${ }_{18}$ El libro se dedica al Humanismo en general, y comienza con trabajos sobre cada uno de los volúmenes de su Obra completa por parte de diversos especialistas ( $c f r$. Butiñá 2003a, 2003b).

${ }^{19}$ Basta remitirse a las publicaciones americanas (de EEUU y Brasil), así como a las múltiples colaboraciones de universidades de Francia, Italia, etc., por parte de latinistas, helenistas, hispanistas.

${ }^{20}$ Como hemos apuntado, ambos representan dos maneras de vivir el fenómeno, el primero en su recepción más impactante y en un ambiente de fuerte adversidad, y el segundo, de una manera más consolidada, en un entorno favorable como es el de la corte del Magnánimo, donde la crítica prácticamente ya de modo unánime sitúa al novelista. Véase la introducción a las ediciones de Lo somni (Metge 2007) y del Curial (2007).

${ }^{21}$ En la introducción de M. Marco (2010) se justifica ampliamente esta lectura.

${ }^{22}$ Las etapas del movimiento en la Corona de Aragón se pueden seguir por reinados (Batllori 1995) o por espacios urbanos (Butiñá 2002c), dado que los núcleos alrededor de los cuales surgen los autores son Barcelona, Nápoles y Valencia sucesivamente. 
siglo XVI, es robusta en el tiempo, aun siendo puntual su estallido principal (el de la Cancillería barcelonesa) y no afluyendo a una salida tan airosa como la de las literaturas vecinas; pero sobre todo hay que valorar que es extremadamente original y valiosa en sus inicios. Cabe añadir que hay que celebrar el incremento de investigaciones por parte de instituciones valencianas sobre ese XV valenciano, de abanico espléndido y vario de producción ${ }^{23}$. Así como hay que resaltar que, a pesar de lo breve -aunque intenso y brillante, ya sólo por las dos obras quizás más destacadas y tan poco leídas, Lo somni y el Curial e Güelfa-, presenta un trazo muy firme y grueso en cuanto al preludio, afirmación y mantenimiento de los rasgos que implica esta línea de renovación, en la que hay que considerar factores que van desde la secularización al predominio de lo humano.

Con la expresión «preludio»o «antecedente»-vocablo más apropiado que precedente-, me estoy refiriendo a las raíces en Ramon Llull (c. 1232-1315) ${ }^{24}$, cuya búsqueda se está produciendo desde puntos muy dispersos ${ }^{25}$. De hecho, ello explica el interés por parte de personalidades renacentistas como Francisco Jiménez de Cisneros (1436-1517) o la recuperación de una figura aparentemente tan medieval como Ramon Llull en autores nítidamente representantes del Humanismo cristiano o en círculos erasmistas ${ }^{26}$. Esto es consecuencia de que el filósofo mallorquín hubiera puesto ya al gentil como modelo frente a los sabios de las otras religiones ${ }^{27}$, lo cual resulta en cierto modo semejante a Dante Alighieri, quien -dando un paso másse deja guiar por un pagano en la Divina Comedia, y al que entienden asimismo en profundidad humanistas tan eximios como Giovanni Boccaccio y Francesco Petrar$\mathrm{Ca}^{28}$. Ahora bien, el gran salto a favor de Bernat Metge consiste en que, para este

${ }^{23}$ Hay que resaltar las actividades investigadoras llevadas a cabo desde la Universidad de Alicante, dirigidas por V. Martines en el Instituto Superior de Investigación IVITRA, así como la Institución de Alfonso el Magnánimo, como organizadora de congresos y editora. Una muestra del nivel de estas investigaciones, que nos invita a referirnos a una obra que no hemos citado, el Tirant lo Blanc, es el estudio de A. Ferrando (2012). O bien la tesis de S. Gros (en prensa).

${ }^{24}$ Estoy trabajando en una línea que los relaciona, sin suponer la relación directa necesariamente (Butiñá en prensa b). Nadie diría que Llull es renacentista pues evidentemente no lo es, pero ofrece rasgos que preparan el advenimiento del Humanismo o coinciden en planteamientos profundos (vid. Butiñá 2013).

25 A esta percepción se aproximan hoy diversos investigadores (J. Ramón Areces, M. A. Coronel, Ò. Santos...). Y hacemos referencia a un par de enclaves donde se subraya este aspecto luliano; de F. Domínguez Reboiras (2000: 133-134) recogemos la siguiente idea: «El pensamiento luliano libre de autoridades y de magisterio escolar, libre también de la tutela clerical, era una ciencia que, aunque Llull no la llevó a sus últimos extremos filosóficos, abría un horizonte insospechado. Aquel horizonte que los humanistas supieron traducir en un nuevo concepto de libertad de estudio e investigación». Por otro lado, en Humanismo catalán. Literatura catalana humanística (Butiñá 2012a) se recogen diversas apreciaciones en esta línea.

${ }^{26}$ Para la aproximación a estos círculos, vid. M. Batllori (1995: 171-190).

27 Desde el decenio de los noventa, indago sobre esta idea a causa de su recepción por parte de Metge en Lo somni, donde actúa como clave la figura de Job como gentil (Butiñá 2006b: 13, 66-104). Dice Bernat Metge: «Job no fou jueu, ans fou ben gentil» (Metge 2007: 86). Hay que advertir que la importancia del gentil luliano como modelo moral la han señalado diversos estudios, como la edición del Libre del gentil e los tres savis (Gutiérrez Gutiérrez y Pernil Alarcón 2007).

${ }_{28}$ Así como estos dos autores asimilan a fondo el mensaje de Dante, sucede con Metge respecto a Llull (Butiñá 2006b: 117-134, 191-218). 
último, el hombre no es ya prioritariamente un ser religioso sino un ser moral; cambio que no plantea por ejemplo Petrarca, como revela el Secretum, y contra lo que sí se revuelve Metge en Lo somni.

Y si esto ocurre detrás de los orígenes del Humanismo propiamente hablando, ya que Ramon Llull, aunque se abre a la gentilidad ${ }^{29}$, no se atreve a reconocer la primacía de los clásicos a causa de la ascendencia del dogma ${ }^{30}$, en los epígonos, en el llamado humanismo cristiano, tenemos la figura consagrada de un Luis Vives, de origen $-\mathrm{y}$ marcado carácter a veces- valenciano ${ }^{31}$. Se ha reiterado constantemente que este Humanismo es efímero porque no desagua en un gran Renacimiento, pero estas consideraciones hacen replantear tal calificativo, a pesar de estar tan acuñado, pues el camino efectuado desde las raíces hasta las últimas consecuciones es ciertamente de peso; algo parecido está pasando con el Humanismo en su conjunto, que grosso modo se alarga hasta la Ilustración.

La línea está, pues, por completar, perfilar y robustecer, intentando darle la consistencia que tiene, sin pretender de todos modos ninguna exageración, pues no ha lugar, ya que es sabido que no hay hechos que supongan revelaciones fulgurantes en ningún movimiento, sino que son fruto del consenso y de tendencias de sensibilidad unánime pero varia; más aún cuando el catalán -aun incluyendo la valiosa producción latina $^{32}$-, como hemos dicho, fue un movimiento que no tuvo la continuidad renacentista que era de esperar comparativamente, pero cuya no-eclosión nunca puede implicar una desvirtuación del movimiento que ha actuado tan enérgicamente de motor. Ahora bien, el influjo recibido en la Corona de Aragón ejerció una función de enlace de gran relevancia, hacia Italia, de donde procede y con la que se relaciona repetidamente, y para con la Península, hacia donde se expande; de modo que difícilmente puede recomponerse llanamente el panorama humanista sin considerar esta pieza que da juego al engranaje (vid. González Rolán 2003; Butiñá y Cortijo Ocaña 2009, 2011).

Del hecho de que sin este enclave no se entiende adecuadamente el Humanismo en su conjunto puede brindar una pequeña muestra, ya citada, el Griselda de Petrarca, que se convierte en pieza emblemática de los gustos de la nueva corriente, pero que ni siquiera en las traducciones por parte de autores de la talla de Philippe de Mézières o Geoffrey Chaucer se advierte una apreciación perspicaz de lo que en rea-

${ }^{29}$ Bajo esta influencia del gentil, en Lo somni de Metge se exponen en primer lugar los argumentos de los clásicos, como se aprecia en el hipotexto de las fuentes (Butiná 2002b: 500).

${ }^{30}$ Lo deja claramente expuesto en las estrofas 36-38 de Lo Desconhort: "Consolar se volc Ramon, emperò felló fo / quan ausí que l'ermità havia opinió / que li filòsof antic, en los quals fe no fo, / sien estats començament de tot ço qui és bo / [...] E doncs, ¿per qual rasó / li filòsof antic hagren mais de visió / en lur enteniment que aquells que aprés só / qui han lig e creença e esperen resurrecció?» (Llull 1988: 119). También en la Doctrina pueril: «Aristòtil e Plató e los altres philosops qui volien haver conexença de Déu sens fe, no pogren, fill, puyar tan alt lur enteniment que poguessen haver declaradament conexença de Déu ne de ses obres ne d'açò per què hom va a Déu» (Llull 1972: 174).

31 Sobre la revalorización de la figura de Luis Vives remitimos a los estudios recientes de M. A. Coronel (2012) y de F. Calero (2012), donde queda subrayada además su valencianidad, que asimismo destaca repetidamente M. Batllori (1995).

32 El estudio más completo, a modo de repertorio, es todavía el de M. Vilallonga (1993). 
lidad suponía aquella novedad, así como tampoco se recoge una resolución sobre quién la marcaba de hecho o quién la debía marcar; sin embargo, se encuentran ambas cosas en la versión del barcelonés Bernat Metge, que inclina la balanza hacia Boccaccio aunque mimetiza la excelente versión petrarquesca (Tavani 1996; Ribera Llopis 1998; Butiñá 2002a).

Por otro lado, las aportaciones de Ramon Llull -que, a pesar de ser un autor considerado tan medieval porque no supo superar la cuadrícula mental propia del escolasticismo, insistimos en que anuncia nuevos tiempos en dimensiones de profundidad- hemos observado ya que se dan en pleno Renacimiento, como ocurre con Nicolás de $\mathrm{Cusa}^{33}$; ello es debido no sólo a su originalidad sino a un afán de apertura ideológica, que se traduce en un prurito por evitar o soslayar los esquemas más retrógrados, especialmente en relación con la aplicación del cristianismo, movimiento asimismo tan renovador. Le faltó evidentemente el atrevimiento de la asunción de los clásicos, pero desde planteamientos hondos, en buena parte de índole moral, se le tiene que considerar, como hemos anticipado, como antecedente ${ }^{34}$. Y reconocerlo en las raíces así como en los epígonos -pues entre otros hemos apuntado que fue recuperado por Metge y por el Cusano- contribuye a iluminar el vacío de estudios en estos extremos.

Con el «ausencia» del título me refiero a estas cuentas pendientes, que perfilarían más y mejor el trazado de esta línea, añadiendo o corrigiendo matices, y también al gran vacío del reconocimiento del movimiento precisamente en el ámbito que le es propio, lo cual es precisamente llamativo cuando el -entusiasmado- arranque partió de estos estudios filológicos: los de M. de Riquer (1934), J. Rubió i Balaguer (1990), M. Batllori (1995). Esta es, pues, a mi entender, una gran ausencia, pues concepto y movimiento se olvidan en el terreno y lengua en que han descollado; es más, sin duda constituye el momento principal de estas letras, pues no debe olvidarse que a pesar de ser una literatura minoritaria y, como hemos dicho, de haberse considerado un movimiento efímero, alcanza desde Ramon Llull ${ }^{35}$ hasta Luis Vives, es decir, nada menos que tres siglos. Junto con el vocablo «ausencias» hay que resaltar además que sigue sin poder explicarse bien al príncipe de las mismas, Bernat Metge, al prescindir del calificativo de humanista, pues quedan sin posibilidad de comprensión obras como su sermón o su debate. Es decir, quien escribe la maravilla del libro I de Lo somni sobre la inmortalidad del alma no puede ser un desalmado -moralmente hablando- o un adocenado repetidor de viejos géneros o un mero intelectual.

${ }^{33}$ En la Proyección histórica del lulismo, M. Cruz Hernández (1977) dedica a Nicolás de Cusa el primer apartado dentro del capítulo «El lulismo renacentista»; y en J. Butiñá (2009) añado un contacto a los expuestos en ese repertorio.

34 Se hace más patente en las obras de audiencia más popular, como el Libre de meravelles (Butiñá 2011). En una lectura atenta de Lo somni, teniendo en cuenta las fuentes, se puede apreciar cómo de los planteamientos de san Agustín pasa a los de Ramon Llull, como si se tratara de un escalón; remito al hipotexto citado.

35 Hago hincapié en el título Detrás de los orígenes del Humanismo: Ramón Llull (Butiñá 2006b), aclarando que no se pretende proponer a Ramon Llull como humanista. 
El concepto de teoría que encabeza este primer libro me da pie para unos últimos comentarios paralelos, pues en una época tan pragmática como la nuestra, no habría que olvidar las características del presente en el que nos movemos, y calibrar una posible vuelta - no ya a los clasicismos, cuyo beneficio se da por supuesto, pero tan alejados por el desconocimiento progresivo de esas lenguas- a estos humanistas, que transmiten aquel bagaje tan limpiamente y que además nos son temporalmente más cercanos ${ }^{36}$. Ante la falta actual de referentes, no sería baldío contar con aquellos -al menos cabe recomendarlo a los filólogos-, pues el Humanismo italiano, tan ligado a sus orígenes latinos, se percibió muy pronto y valientemente en la cancillería de Barcelona y poco a poco, con los avatares que hemos indicado, fue impregnando la Península Ibérica. La cuenta pendiente, pues, se sigue situando en el Mediterráneo, fuente inagotable hasta el momento de renaceres.

La fuerza de un movimiento que estamos prácticamente descubriendo o recomponiendo podría quizás -aunque sea utópico hay que dejar constancia- hacer de revulsivo para las Humanidades occidentales, tan agotadas que ya no pueden reaccionar dentro de un panorama de alta mediocridad. Lo cual incita a remontarse a un momento de ruptura y de autenticidad, que eppur si muove ${ }^{37}$.

Ello invita a unas reflexiones finales acerca del movimiento humanista ${ }^{38}$, en el que hay que destacar un rasgo importante comentado recientemente pero poco señalado, aunque marcó ya el Humanismo temprano: el carácter mediterráneo. Y lo hacemos con unas palabras del profesor A. Musco, que apuntan hacia algunos comentarios expuestos en las líneas anteriores: por un lado, el rescate de este Humanismo, y, por otro, que las raíces se pueden reconocer en el filósofo mallorquín. Así pues, valgan para ilustrar el concepto de la mediterraneidad en relación con Ramon Llull:

Noi umanisti mediterranei siamo chiamati in modo prepotente a ridisegnare gli schemi dei saperi entro i quali il mondo cosiddetto occidentale ha vissuto dalla rivoluzione francese e che ha imposto al resto dell'universo, animato o inanimato che sia: ci chiama a questo ogni giorno, ogni pezzo di natura in cui viviamo e che ci chiede vendetta e giustizia per i disastri che l'uomo opera [...] ci chiama a questo ogni pauper, giovane o vecchio che sia, antico o nuovo che sia, invocando giustizia! E' non è certo

${ }^{36}$ La función de transmisión, de la que estos hacen réplica, se hace palpable y de modo emocionante en el canto 21 del Purgatorio de la Divina Comedia, en que Estacio reconoce que Virgilio le condujo a la divinidad.

37 Evidentemente no se trata de resucitar un pasado, pretensión siempre tentadora pero en la actualidad inalcanzable y no recomendable, sino de estudiar y de beber en un caudal que nos ha sido confiado a los occidentales. Acerca de la prevención de aquella aspiración, tomo de V. Camps (2012: 4) estas palabras, aclarando un texto de José Ferrater Mora, quien, en el escrito «Reflexiones sobre Cataluña», recogido en el volumen Tres mundos: Cataluña, España, Europa, pone en guardia contra la tendencia a contemplar el pasado como lo que hubiera podido ser y no fue, pues solo así se deja de vivir obsesionado por el pasado: «Sólo si nos liberamos de la "enfermedad del pasado", del deseo inmarcesible de "renacer" constantemente, dejaremos de interpretar lo que fue como algo que determina irremediablemente el futuro».

${ }^{38}$ Insistiendo, por último, sobre la dignitas mundi, cabe remitir al prólogo de F. Domínguez Reboiras (2000) al De homine luliano. 
giustizia che circa un terzo della popolazione mondiale pensa di avere il diritto di consumere per tutti, lasciando alla fame e alla sete gli altri due terzi e più dell'umanità! In questo grande progetto, in questa sfida che nasce spontanea dalle acque, dai cieli e dalla infinita storia dei saperi mediterranei, gli scritti e l'opera di Raimondo Lullo (ma non solo di Lullo) sono una miniera infinita: una eredità grande che solo chi, come Lullo, sapeva pensare e ragionare per grandi disegni e non per segmenti sparsi, poteva lasciare a noi tutti. (Musco 2011: 470) ${ }^{39}$

Humanismo mediterráneo con una función posible y necesaria de rediseño del esquema de los saberes, que se debería sentir como imperativo, y que al menos sirviera para el mejor conocimiento de nuestra civilización occidental en la encrucijada hacia la Edad Moderna - ubicada en el feliz rescate de la Antigüedad gracias a los humanistas $-\mathrm{y}$ evidentemente también para la mejor comunicación peninsular ${ }^{40}$.

Y para estrechar el discurso filológico en el cierre, este Humanismo mediterráneo presenta raíces claras en dos autores muy representativos de sus orígenes, Dante y Llull ${ }^{41}$-adalides del cristianismo-, aunque provengan ya de Platón y de san Agustín. Por tanto, son un nudo firme que cohesiona el conjunto europeo. Aunque curiosamente la cohesión en cuanto al Humanismo ha ocurrido en la mayor parte gracias a Petrarca, quien no fue renovador en profundidad en los contenidos sino en la metodología, con la que selló muy radicalmente el cambio, y que es quien prácticamente canaliza y acapara todavía la «marca» humanista. Una vuelta a aquellos otros orígenes con señas peninsulares, pues, se impone tras la lectura del texto italiano que hemos recordado.

39 Asimismo, vid. Ò. Santos Sopena (2013).

${ }^{40} \mathrm{Ni}$ que decir tiene que la Península no se escinde ante el concepto mediterráneo por hallarse a mayor o menor distancia del Mare Nostrum; los fenómenos culturales son amplios y responden al unísono. Ello no obsta a que además la cultura gallega y portuguesa participen del concepto atlántico.

${ }^{41}$ Tomo unas líneas de una reseña de Ò. Santos Sopena al libro de J. Butiñá y A. Cortijo Ocaña (2012): «Autor primordial [Llull] para entender la globalidad Mediterránea que aporta el Humanismo; sobre todo si pensamos en el misticismo de su contemplación, propio de la visión franciscana tan cercana a una actitud y a un tono realista. Por ejemplo, el Libre de Santa Maria (1290) y el Desconhort (1295) plantean ya un antecedente humanista global, que es crucial para señalar el intercambio literario, lingüístico, cultural, filosófico y social propio de la corriente humanística» (Santos Sopena 2012). 